China Ocean Eng., 2018, Vol. 32, No. 3, P. I

DOI: https://doi.org/10.1007/s13344-018-0039-4, ISSN 0890-5487

http://www.chinaoceanengin.cn/ E-mail: coe@nhri.cn

\title{
10th International Conference on Asian and Pacific Coasts (APAC2019), Hanoi, Vietnam, September 25-28, 2019
}

\section{Introduction}

The International Conference on Asian and Pacific Coasts (APAC) is an international conference to promote academic and technical exchange on coastal related studies that include coastal engineering and coastal environmental problems, among the Asian and Pacific countries/regions. APAC is jointly supported by the Chinese Ocean Engineering Society (COES), the Coastal Engineering Committee of the Japan Society of Civil Engineers (JSCE), and the Korean Society of Coastal and Ocean Engineers (KSCOE). A wide range of organizations from Asian and Pacific countries/regions are its active participants or sponsors. The Conference is held once every two years.

The 10th International Conference on Asian and Pacific Coasts (APAC2019), to be held in Hanoi, Vietnam in September 25-28, 2019, will extend the series of biennial conference with the first one being held in Dalian, China in 2001 by the name of Asian and Pacific Coastal Engineering (APACE). To reflect a broader scope, the conference was renamed to Asian and Pacific Coasts (APAC) and it was subsequently held every two years in different countries and regions including Japan (2004), Korea (2005), China (2007), Singapore (2009), HongKong SAR (2011), Indonesia (2013), India (2015), and the Philippines (2017). These conferences have acted as a welcome forum to report and discuss the latest advancements in Coastal, Ocean and Port Engineering and as such, have always been highly valued by all participants. Undoubtedly, APAC 2019 hosted by Thuyloi University (Hanoi, Vietnam) will provide an opportunity for making numerous personal and professional exchanges in Vietnam and overseas. The theme of this conference is "Living with nature, coping with coastal changes".

\section{Call for papers and conference themes}

Prospective authors are invited to submit abstracts of no more than 500 words in English before 31 December 2018. The relevant conference themes include, but are not limited to:

- Ocean wave, tides, storm surge and tsunami

- Beach erosion and coastal sediment transport

- Coastal and estuarine hydrodynamics

- Lowland development and reclamation

- Beach development and coastal protection

- Marine ecology and coastal environments

- Marine and offshore renewable energy

- Climate change and coastal adaptation

- Coastal hazards and risk assessment

- Mekong Delta, beach erosion and saltwater intrusion

\section{Important dates}

Call for abstracts 15 May 2018

Abstract submission deadline 31 Dec. 2018

Notification of abstract acceptance 31 Jan. 2019

Full paper submission deadline 30 Apr. 2019

Notification of full paper acceptance

30 Jun. 2019

\section{Conference secretariat}

Assoc. Prof. Nguyen Cao Don

Thuyloi University,

175 Tay Son Str., Dong Da, Hanoi, Vietnam

Email: apac2019@tlu.edu.vn

Phone: +84243654 1053

Fax: +84243653 3351

Website: http://apac2019.tlu.edu.vn/ 